Research Article

\title{
Computer Vision Syndrome among Undergraduate Medical Students in King Abdulaziz University, Jeddah, Saudi Arabia
}

\author{
Ghufran A. Abudawood ${ }^{D},{ }^{1}$ Heba M. Ashi ${ }^{D},{ }^{2}$ and Nawaf K. Almarzouki ${ }^{1}{ }^{1}$ \\ ${ }^{1}$ Department of Ophthalmology, King Abdulaziz University Hospital, Jeddah 21589, Saudi Arabia \\ ${ }^{2}$ Department of Public Health, Faculty of Dentistry, King Abdulaziz University Hospital, Jeddah, Saudi Arabia \\ Correspondence should be addressed to Ghufran A. Abudawood; g.abudawood@gmail.com
}

Received 19 August 2019; Revised 9 March 2020; Accepted 10 March 2020; Published 1 April 2020

Academic Editor: Carsten H. Meyer

Copyright (c) 2020 Ghufran A. Abudawood et al. This is an open access article distributed under the Creative Commons Attribution License, which permits unrestricted use, distribution, and reproduction in any medium, provided the original work is properly cited.

\begin{abstract}
Introduction. Computer vision syndrome (CVS) is "a complex of eye and vision problems related to near work experienced during computer use." It is one of the rising health concerns related to technology (cell phones and tablets) due to continuous use of computers among students. The aim of this study was to determine the prevalence of CVS, associated risk factors, and commonly associated symptoms and to assess the awareness and proper practice of using computers for studying. Methods. A cross-sectional descriptive study was conducted among 651 undergraduate medical students in King Abdulaziz University, Jeddah, Saudi Arabia. An electronic survey was conducted to collect the data. Data were analyzed using SPSS v21. The chi-square test (Fisher's exact test when required) was used to study the significance of associations. $P$ value $<0.05$ was considered statistically significant. Results. High prevalence of CVS was observed, in which 95\% (558) reported at least one symptom during studying using computers. Most frequently reported symptoms were excessive tearing and neck, shoulder, or back pain. Female students had a higher risk of CVS $(P=0.003)$. Students who are myopic or hyperopic showed no association. Astigmatism was associated significantly with CVS $(P=0.03)$. Using spectacles or contact lens showed no association. Students with dry eye disease revealed a significant association with CVS $(P=0.01)$. The most significant risk factors related to the daily usage of computer were longer duration of studying $(P<0.001)$, short distance from the screen $(P<0.05)$, and high brightness of the screen $(P<0.05)$. The most significant preventive measure taken to relieve the symptoms was applying the 20-20-20 rule. Conclusion. CVS is common among medical students; significant risk factors need to be addressed to reduce the symptom and to ensure a better productivity of work. It is a necessity to raise awareness among medical students regarding computer-related health problems.
\end{abstract}

\section{Introduction}

In this modern generation, the use of computers became an essential tool to perform everyday tasks at work and at home. This holds true regardless of the user's profession or occupation. The development of technology in education made a noticeable transformation in the methods of teaching, presenting information, and sources for studying. However, this convenient lifestyle still raised a health-related concern [1-3]. Among the health-related aspects is a condition known as computer vision syndrome (CVS). The American Optometric Association (AOA) defined computer vision syndrome as "a complex of eye and vision problems related to near work experienced during computer use." [1]

Almost $75 \%$ of a person's daily activities include computer usage [4]. Globally, around 60 million computer workers experience discomfort from CVS [5]. Nearly 45 million workers use computers by staring at the screen for hours continuously [6]. A survey study among American optometrists found that $14.25 \%$ of patients who visited optometry clinic were suffering primarily from symptoms associated with computer use [7]. Nowadays, university students including medical students are spending more time staring at the screen for studying and for research work. There have been several studies reporting an increased 
prevalence of CVS among computer users, specifically medical students $[8,9]$.

CVS symptoms occur when there is a need to increase the visual demand to the extent it exceeds the person's visual ability [1]. The image on the screen is produced by thousands of pixels combined to form an image, in which the margins are not sharp and is dependent on the resolution, the contrast of the background, and glare or reflection from the screen. These factors in contrary to printed documents increase the visual demand in order to perceive good images $[1,10,11]$. In addition, CVS can also be explained by decreased blinking reflex while staring at the screen, leading to exaggerating dry eyes [11]. Dry eyes have been proved to play as a major contributor to CVS symptoms $[8,12]$. The underlying cause of dryness needs to be diagnosed and treated accordingly. Users who are known to have dry eyes are recommended to use lubricating eye drops to minimize the symptoms of CVS $[1,11]$. Other factors such as the duration of usage, taking breaks, distance from the screen, screen brightness, and sitting posture were discussed in previous studies and were considered as known risk factors of CVS [8, 13-16].

Although most of CVS symptoms are transient and no permanent visual damage was reported in previous studies, some workers still experience visual difficulty after work $[1,17]$. The eyes and musculoskeletal discomfort associated with CVS may result in reduced productivity by $40 \%$ of users $[10,18]$. Additionally, Shantakumari et al. noted that more than $70 \%$ of university students were having frequent interruption of computer work caused by CVS symptoms [16]. Therefore, this issue needs to be addressed to improve work and study productivity and avoid discomfort symptoms related to computers.

The aim of this study was to determine the prevalence of CVS among undergraduate medical students, associated risk factors, most commonly associated symptoms, and to assess the proper practice of using computers for studying among medical students. The findings of this study will help recognize the problem and will raise the awareness towards their daily practice and implement preventive measures to avoid CVS-related symptoms.

\section{Methods}

A cross-sectional descriptive study conducted included 651 undergraduate medical students from the second to the sixth year in King Abdulaziz University, Jeddah, Saudi Arabia. Participants were enrolled by nonprobability convenience sampling. An electronic survey adapted from previous literature research on CVS was used for data collection $[6,8,16]$. CVS symptoms are categorized into ocular and extraocular. Ocular symptoms include dry eyes, red eye, burning sensation, foreign body sensation, blurred vision and increased sensitivity to light, excessive tearing, itching, ocular pain, change in visualizing colors, and double vision. Extraocular symptoms include headache; neck, shoulder, or back pain; and numbness of the hands or fingers $[6,8,9,14]$. The survey included demography, refractive errors, using spectacle or contact lens for vision correction, duration of studying using computers, frequency and duration of breaks, seating posture and source of lightning, using antiglare screen, frequency of CVS symptoms experienced on continuous computer work, and preventive measures taken to reduce the symptoms. The inclusion criteria were undergraduate medical students who use their laptops or tablets during studying for at least one month prior to the study. Data were analyzed using Statistical Package for Social Sciences (SPSS v21). The chi-square test (Fisher's exact test when required) was used to study the significance of associations. $P$ value $<0.05$ was considered statistically significant.

\section{Results}

A total of 651 participants were invited to participate in the study; $90.2 \%$ (587) of the students use computers for studying and were included. $54.3 \%$ (319) were females, and $45.7 \%$ (268) were males; the age ranged between 19 and 27 years, with a mean of 21.65 years. High prevalence of CVS was observed, in which 95\% (558) reported at least one symptom of CVS during studying using computers. In regard to demographical data in this study, female gender (54.3\%) (319) was observed to have higher risk of CVS $(P=0.003)$.

In regard to refractive errors, $22.6 \%$ (147) was known to have myopia, $14.7 \%$ (96) hyperopia, and $11.7 \%$ (76) astigmatism. 40.9\% (266) of students wear spectacle, and 10.4\% (68) wear contact lens for vision correction during studying. $15.3 \%$ (90) were known to have dry eye disease.

The presence of refractive errors including myopia and hyperopia was not associated with CVS, but astigmatism showed significant association with CVS $(P=0.03)$, specifically headache and increased sensitivity to light $(P=0.001$ and 0.01 , respectively). The use of spectacles or contact lens for vision correction during studying showed no significant association. Students who were known to have dry eye disease (15.3\%) (90) were associated significantly with CVS $(P=0.01)$.

The most frequently reported ocular symptoms were excessive tearing (20.6\%) (121), eye dryness (20.3\%) (119), itching (18.9\%) (111), increased sensitivity to light (16.2\%) (95), eye redness (15.1\%) (89), burning sensation (15\%) (88), pain (14\%) (82), foreign body sensation (12.2\%) (72), blurred vision (11.4\%) (67), change in visualizing colors (6.5\%) (38), and double vision (5.4\%) (30). The most frequently reported extraocular symptoms were neck, shoulder, or back pain (39.7\%) (233); headache (30.1\%) (177), and numbness of the hands or fingers (14.8\%) (87) (see Figures 1 and 2).

The association between the presence of CVS and each risk factor was analyzed in this study, in which the most statistically significant risk factors were duration of studying $(P<0.001)$, distance from the screen $(P<0.05)$, and brightness of the screen $(P<0.05)$ (see Table 1$)$.

The correlation between each risk factor and each symptom of CVS was also analyzed; the long duration of time spent during studying (three or more hours per day) was the most significant risk factor reported in $82.3 \%$ (459), which was correlated significantly with most of CVS 


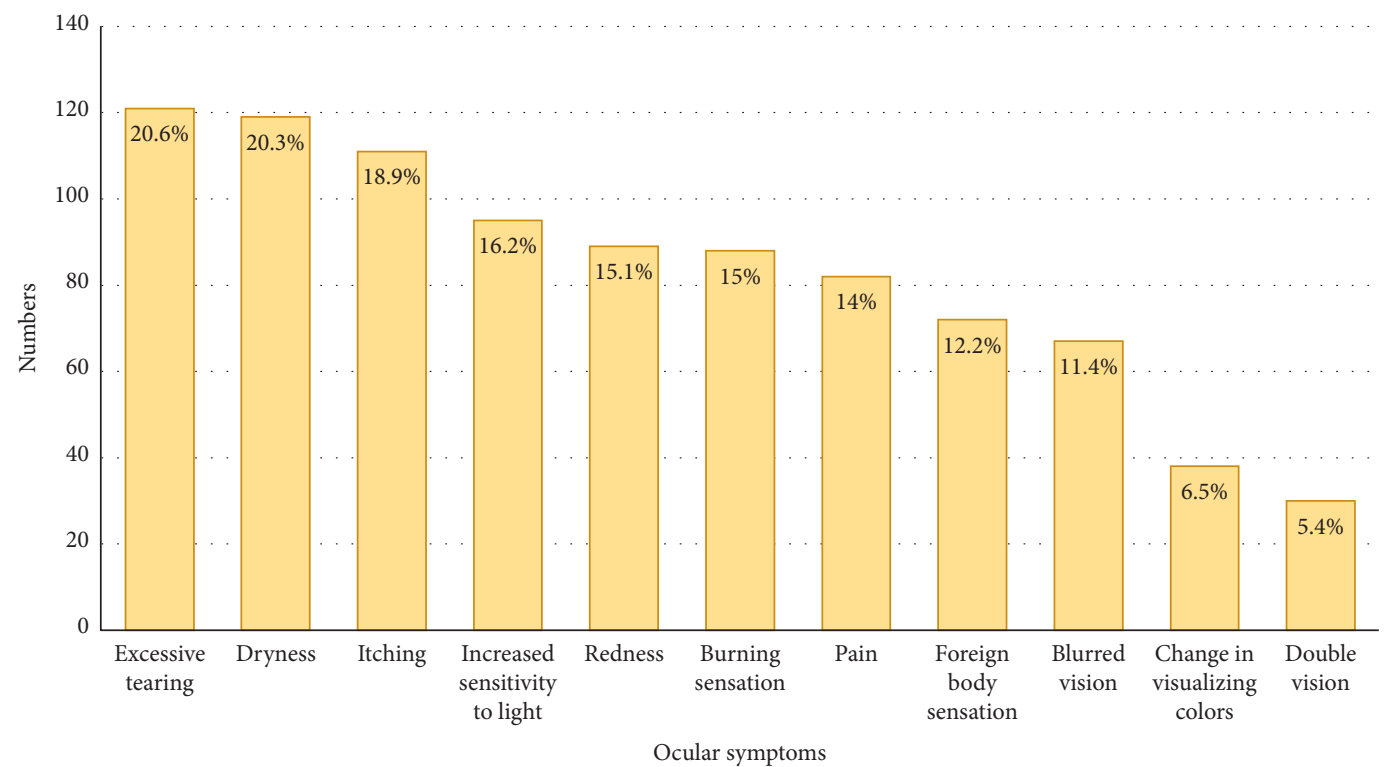

FIGURE 1: Frequency of ocular symptoms of computer vision syndrome. Excessive tearing was the most commonly reported symptom.

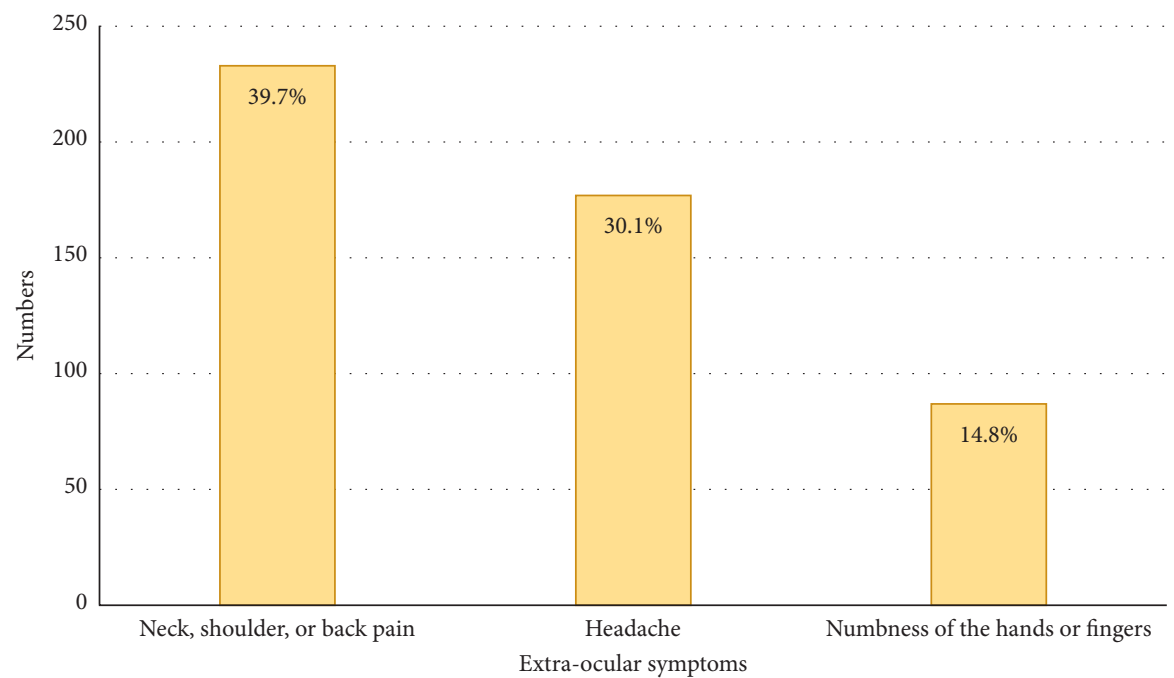

FIGURE 2: Frequency of extraocular symptoms of computer vision syndrome. Neck, shoulder, or back pain was the most commonly reported symptom.

symptoms, burning sensation, foreign body sensation, headache, blurred vision, dryness, eye pain, itching, tearing, increased sensitivity to light, eye redness, numbness of the hands and fingers, and neck, shoulder, or back pain $(P<0.05)$.

Most students were taking frequent breaks during studying (90.8\%) (506), with the most reported frequency of every 30-60 minutes (43.4\%) (242). Although the frequency of taking breaks was not associated significantly with CVS, those who were not taking breaks during studying (8.8\%) (52) associated significantly with tearing, double vision, change in visualizing colors, and neck, shoulder, or back pain $(P<0.05)$. Short distance from the screen (less than arm and forearm length) was significantly associated with headache and neck, shoulder, or back pain $(P<0.01)$, in which $62.6 \%(368)$ of students kept a short distance from the screen during studying. The posture during studying was not associated with any CVS symptoms.

In regard to the level of the screen, a same level of the screen from the eyes or higher level in $41 \%$ (229) were associated significantly with increased sensitivity to light, double vision, and change in visualizing colors $(P<0.05)$. Only $18.3 \%$ (102) of the students were studying using sources of lightning other than the lights from the ceiling (window light, desk lamp, and screen light in a dark room), in which it was significantly associated with blurred vision, eye redness, foreign body sensation, double vision, and change in visualizing colors $(P<0.05)$. Higher brightness of the screen in $21 \%$ (97) was correlated significantly with increased sensitivity to light $(P<0.01)$. The majority of students were not using screen filter (86.7\%) (484), which 
TABle 1: Association between risk factors and computer vision syndrome.

\begin{tabular}{|c|c|c|c|c|c|c|c|c|}
\hline \multirow{3}{*}{ Variables } & \multirow{3}{*}{ Groups } & \multicolumn{4}{|c|}{$\begin{array}{l}\text { Computer vision } \\
\text { syndrome }\end{array}$} & \multirow{2}{*}{\multicolumn{2}{|c|}{ Total }} & \multirow{3}{*}{$P$ value } \\
\hline & & \multicolumn{2}{|c|}{ Positive } & \multicolumn{2}{|c|}{ Negative } & & & \\
\hline & & $N$ & $(\%)$ & $N$ & $(\%)$ & $N$ & $(\%)$ & \\
\hline \multirow{3}{*}{ Duration of studying } & 1-2 hours per day & 99 & 87.6 & 14 & 12.4 & 113 & 100 & \multirow{3}{*}{$0.001^{*}$} \\
\hline & 3-4 hours per day & 192 & 95 & 10 & 5 & 202 & 100 & \\
\hline & More than 4 hours per day & 267 & 98.2 & 5 & 1.8 & 272 & 100 & \\
\hline \multirow{2}{*}{ Taking breaks } & Yes & 506 & 94.9 & 27 & 5.1 & 533 & 100 & \multirow{2}{*}{1.0} \\
\hline & No & 52 & 96.3 & 2 & 3.7 & 54 & 100 & \\
\hline \multirow{3}{*}{ Frequency of taking breaks } & Every 30 minutes or less & 159 & 94.6 & 9 & 5.4 & 168 & 100 & \multirow{3}{*}{0.68} \\
\hline & Every $30-60$ minutes & 242 & 94.5 & 14 & 5.5 & 256 & 100 & \\
\hline & Every 60 minutes or more & 157 & 96.3 & 6 & 3.7 & 163 & 100 & \\
\hline \multirow{2}{*}{ Distance from the screen } & $>$ Arm and forearm length & 190 & 92.2 & 16 & 7.8 & 206 & 100 & \multirow{2}{*}{$0.02^{*}$} \\
\hline & $<$ Arm and forearm length & 368 & 96.6 & 13 & 3.4 & 381 & 100 & \\
\hline \multirow{3}{*}{ Posture } & Sitting & 233 & 94.0 & 15 & 6.0 & 248 & 100 & \multirow{3}{*}{0.56} \\
\hline & Lying & 20 & 95.2 & 1 & 4.8 & 21 & 100 & \\
\hline & Both & 305 & 95.9 & 13 & 4.1 & 318 & 100 & \\
\hline \multirow{3}{*}{ Level of the screen } & Below level of the eyes & 329 & 94.5 & 19 & 5.5 & 348 & 100 & \multirow{3}{*}{0.60} \\
\hline & Same level of the eyes & 216 & 95.6 & 10 & 4.4 & 226 & 100 & \\
\hline & Above level of the eyes & 13 & 100 & 0 & 0.0 & 13 & 100 & \\
\hline \multirow[b]{2}{*}{ Source of lightning } & From the ceiling/wall & 456 & 95.2 & 23 & 4.8 & 479 & 100 & \multirow[b]{2}{*}{0.74} \\
\hline & $\begin{array}{l}\text { Other sources; windows, desk lamp, } \\
\text { or in a dark room }\end{array}$ & 102 & 94.4 & 6 & 5.6 & 108 & 100 & \\
\hline \multirow{3}{*}{ Brightness of the screen } & Very bright & 97 & 99.0 & 1 & 1.0 & 98 & 100 & \multirow{3}{*}{$0.04^{*}$} \\
\hline & Bright & 247 & 92.9 & 19 & 7.1 & 266 & 100 & \\
\hline & Dull or dark & 214 & 96.0 & 9 & 4.0 & 223 & 100 & \\
\hline \multirow{2}{*}{ Using screen filter/antiglare screen } & Yes & 74 & 96.1 & 3 & 3.9 & 77 & 100 & \multirow{2}{*}{1.0} \\
\hline & No & 484 & 94.9 & 26 & 5.1 & 510 & 100 & \\
\hline
\end{tabular}

${ }^{*} P$ value statistically significant.

correlated significantly with itching, double vision, and change in visualizing colors $(P<0.05)$.

The impact of preventive measures taken by students during studying using computers and the presence of CVS showed that applying the 20-20-20 rule was the most significant preventive measure $(P=0.01)$, followed by proper location of the screen $(P=0.04)$. Other measures showed no significant association (see Table 2).

\section{Discussion}

Among the 587 students enrolled in the study a high prevalence of CVS 95\% was reported (558). This is in accordance with a study by Hassan et al. who reported a prevalence of $90.5 \%$ among medical students in Pakistan [8]. Reddy et al. also provided a prevalence of $89.9 \%$ among university students in Malaysia [14]. However, a lower prevalence was observed in other studies among engineering and medical students (67.2\% and $77.4 \%$, respectively) $[3,13]$.

In regard to gender, females were observed to have more risk of CVS. This association agrees with the findings by Guillon and Maïssa who studied the effect of gender on tear film evaporation, which showed a significant high evaporation rate in females, thus higher risk of CVS [19]. In addition, Straker et al. studied the association between gender and posture during computer use, which concluded that females had greater prevalence of neck/shoulder pain
[20]. Other studies in Sri Lanka, India, and United Arab Emirates also support the significantly high CVS prevalence among female computer workers, with significantly higher headache and blurred vision incidence $[9,15,16]$. In contrast, males were found to have higher risk of redness, burning sensation, blurred vision, and dry eyes among medical and engineering students in India [9].

Students in this study were relatively young, with a mean age of 21.65 years. No significant associations were found between the year of medical school and the age with CVS. However, Ranasinghe et al. found a significantly higher prevalence of CVS among those aged more than 40 years compared with those aged less than 20 years [15]. Guillon and Maïssa also noted a significantly higher tear film evaporating rate in patients older than 45 years compared with younger individuals, which exaggerate symptoms of dryness associated with CVS [19].

Refractive errors including myopia and hyperopia showed no significant association with CVS. However, astigmatism was associated significantly with CVS symptoms. Previous experimental studies showed a significant increase in symptoms in individuals with uncorrected residual astigmatism [21, 22]. If refractive errors are uncorrected including myopia, hyperopia, and astigmatism, they contribute to the symptoms of CVS [1].

The use of spectacles or contact lens for vision correction during studying showed no significant association in our 
TABLE 2: Association between preventive measures taken by students during studying using computers and the presence of computer vision syndrome.

\begin{tabular}{|c|c|c|c|c|c|c|c|c|}
\hline \multirow{3}{*}{ Variable } & \multirow{3}{*}{ Groups } & \multicolumn{4}{|c|}{$\begin{array}{l}\text { Computer vision } \\
\text { syndrome }\end{array}$} & \multicolumn{2}{|c|}{ Total } & \multirow{3}{*}{$P$ value } \\
\hline & & \multicolumn{2}{|c|}{ Positive } & \multicolumn{2}{|c|}{ Negative } & \multirow{2}{*}{$N$} & \multirow{2}{*}{$(\%)$} & \\
\hline & & $N$ & $(\%)$ & $N$ & $(\%)$ & & & \\
\hline \multirow{3}{*}{$\begin{array}{l}20-20-20 \text { rule } \\
\text { Taking short breaks every } 20 \text { minutes for } 20 \text { seconds } \\
\text { and looking at objects at least } 20 \text { feet away }\end{array}$} & Always/very often & 198 & 91.7 & 18 & 8.3 & 216 & 100 & \multirow{3}{*}{$0.01^{*}$} \\
\hline & Occasionally & 145 & 98.0 & 3 & 2.0 & 148 & 100 & \\
\hline & Rarely/never & 215 & 96.4 & 8 & 3.6 & 223 & 100 & \\
\hline \multirow{3}{*}{ Frequent blinking } & Always/very often & 147 & 93.6 & 10 & 6.4 & 157 & 100 & \multirow{3}{*}{0.40} \\
\hline & Occasionally & 107 & 97.3 & 3 & 2.7 & 110 & 100 & \\
\hline & Rarely/never & 304 & 95.0 & 16 & 5.0 & 320 & 100 & \\
\hline \multirow{3}{*}{$\begin{array}{l}\text { Location of the screen } \\
\text { More than arm and forearm length from the eyes } \\
\text { and below the level of the eyes }\end{array}$} & Always/very often & 196 & 92.5 & 16 & 7.5 & 212 & 100 & \multirow{3}{*}{$0.04^{*}$} \\
\hline & Occasionally & 151 & 95.0 & 8 & 5.0 & 159 & 100 & \\
\hline & Rarely/never & 211 & 97.7 & 5 & 2.3 & 216 & 100 & \\
\hline \multirow{3}{*}{$\begin{array}{l}\text { Lightning } \\
\text { Using an overhead lighting from ceiling other than a } \\
\text { desk lamp or light hitting directly on the eyes }\end{array}$} & Always/very often & 309 & 95.1 & 16 & 4.9 & 325 & 100 & \multirow{3}{*}{0.95} \\
\hline & Occasionally & 85 & 94.4 & 5 & 5.6 & 90 & 100 & \\
\hline & Rarely/never & 164 & 95.3 & 8 & 4.7 & 172 & 100 & \\
\hline \multirow{3}{*}{$\begin{array}{l}\text { Sitting location } \\
\text { Avoiding sitting at a location where there is direct blow } \\
\text { of air to the eyes or where there is light reflected on the screen }\end{array}$} & Always/very often & 282 & 95.3 & 14 & 4.7 & 296 & 100 & \multirow{3}{*}{0.91} \\
\hline & Occasionally & 98 & 94.2 & 6 & 5.8 & 104 & 100 & \\
\hline & Rarely/never & 178 & 95.2 & 9 & 4.8 & 187 & 100 & \\
\hline \multirow{3}{*}{ Use of an antiglare screen } & Always/very often & 103 & 92.8 & 8 & 7.2 & 111 & 100 & \multirow{3}{*}{0.39} \\
\hline & Occasionally & 46 & 93.9 & 3 & 6.1 & 49 & 100 & \\
\hline & Rarely/never & 409 & 95.8 & 18 & 4.2 & 427 & 100 & \\
\hline
\end{tabular}

${ }^{*} P$ value statistically significant.

study. These results were contradicted by Ranasinghe et al. who found a significantly higher CVS among contact lens wearers; furthermore, contact lens wearers are more prone to dryness which exacerbate CVS symptoms [12, 15]. While Reddy et al. found university students who wear spectacles had significantly more CVS symptoms than those who do not wear spectacles during computer use [14]. Furthermore, a study in Chennai revealed a significantly higher risk of developing headache and blurred vision among students wearing corrective lens, including both spectacles and contact lens [9].

Students who were known to have dry eye disease (15.3\%) (90) were associated significantly with CVS. This is in line with a study carried out among Japanese office workers which concluded a significantly high prevalence of dry eye disease among video display terminal users [23]. This is explained by the reduced blinking reflex while seated in front of the screen for a long time, which contributes to improper tear production, thus exaggerating dry eye disease [9]. In some patients, dryness is associated with systematic disease such as Sjogren's syndrome and rheumatoid arthritis [12].

The most frequently reported ocular symptoms were excessive tearing in $20.6 \%$ followed by feeling of dryness in $20.3 \%$. The former was significantly correlated with not taking breaks and with longer duration of studying. Higher frequency was observed by Hassan et al. in $49.2 \%$ of medical students [8]. Other ocular surface-related symptoms included itching, redness, burning sensation, and foreign body sensation $(18.9 \%, 15.1 \%, 15 \%$, and $12.2 \%$, respectively). Burning sensation was reported in higher frequency compared with our study in $33 \%$ of medical and dental students, $54.8 \%$ of university students, and $32.3 \%$ of medical students $[9,13,16]$. Ocular pain was experienced by $14 \%$ of students and blurred vision in $11.4 \%$, both associated significantly with improper room lightning. Blurred vision could be explained also by inaccurate accommodative response and failure to relax after prolonged near-vision activities $[10,12]$. Increased sensitivity to light was observed in only $6.2 \%$, specifically and significantly among students using higher screen brightness and higher level of the screen from the eyes. Change in color perception and double vision were reported by $6.5 \%$ and $5.4 \%$, respectively, which were correlated significantly with improper room lightning and not using screen filters.

Among the extraocular symptoms, neck, shoulder, or back pain was the most common symptom in $39.7 \%$, followed by headache in $30.1 \%$, and numbness of the hands or fingers in $14.8 \%$. The first two were associated significantly with short distance from the screen. However, headache was the most commonly reported extraocular symptom in other studies $[13,14,16]$. Headache is explained in CVS patients by the constant need to adjust the eyes by contracting the extraocular muscles and ciliary muscles to maintain the lens in the accommodating phase. Throughout the time, focusing and refocusing are required repeatedly to see in different distances from the screen to the keyboard and to work documents, leading to eye muscle fatigue causing headache $[15,17]$. Other musculoskeletal symptoms are well related to improper seating posture and placement of the screen $[10,17]$. It is noteworthy that extraocular symptoms were reported more frequently than ocular symptoms in our study. This is in line with a study performed by Logaraj et al., in which neck and shoulder pain and headache were more frequently reported than ocular symptoms [9]. In contrast, a study by Noreen et al. indicated that ocular complaints 
(55\%) were higher than headache, and neck, shoulder, or back pain (12\%) in medical and dental students [13].

The most statistically significant risk factors were duration of studying, followed by distance from the screen and brightness of the screen. Duration of studying using computers was the most significant risk factor, in which the longer the time spent, the more prevalent and extent are symptoms. This finding is consistent with the findings of Hassan et al. and a report by the American Optometric Association [1, 8]. Furthermore, Noreen et al. and Logaraj et al. reported that among CVS-positive group, students who spent more than four hours were at significantly at higher risk of CVS than who spent less than four hours $[9,13]$. Strengthening the fact, Reddy et al. found a significantly higher CVS among students who used computers for more than two hours [14]. It was also observed that the longer the duration, the longer the complaint last even after work [13].

The frequency of taking breaks were not associated significantly with CVS, which is supported by the same finding in previous studies [13-15]. In contrast, Hassan et al. found that taking short breaks every 30 minutes every hour decreases visual discomfort [8]. Students who were not taking breaks at all during studying (8.8\%) (52) associated significantly with tearing, and neck, shoulder, or back pain. Strengthening the fact, visual symptoms reported significantly among users who were not taking frequent breaks in previous studies $[8,9,16]$.

Majority of the students (64.9\%) (381) viewed computers at a distance of less than arm and forearm length, which resulted significantly in more CVS symptoms. Similarly, Hassan et al. found that students who viewed at a distance of less than $50 \mathrm{~cm}$ were prone to higher risk of CVS [8]. Shantakumari et al. added that the prevalence of headache decreased in students who viewed the screen at a distance more than $50 \mathrm{~cm}$ [16]. In contrast, distance from the monitor was not associated with CVS in a study performed in Sri Lanka among computer workers [15].

Nevertheless, the recommended viewing distance was suggested to be 20-28 inches by the American Optometric Association [1].

A study carried out by Straker et al. found that musculoskeletal complaint gets worse by sitting posture [20]. However, no association was noted in our study. The level of the screen from the eyes was not associated with developing of CVS. More than half of the students were having good studying habit by locating the screen below the level of the eyes. Improper viewing angles are reported as a risk factor for CVS in previous studies [10,24]. It is recommended to place the screen $10-20^{\circ}$ below the level of the eyes. Higher gaze angles expose more area of the cornea and conjunctiva, resulting in more ocular surface-related symptoms with an increased tear evaporation rate $[10-12,15]$. Strengthening the fact, Reddy et al. found significant reduction in CVS symptoms when the screen is viewed below the eye level [14].

No significant association was noted regarding the source of lightning and development of CVS in this study. Nevertheless, the screen brightness and the room lighting should be balanced, working facing an unshaded window or using desk lamps or an overhead lightning contribute significantly to CVS problems [1]. Screen brightness was associated significantly with the developing of CVS in our study. Specifically, higher brightness was correlated significantly with increased sensitivity to light. Similarly, higher brightness increased the incidence of headache among university students in Ajman. In addition, using computers in dark screen increased the incidence of dry eyes as found by Shantakumari et al. study [16]. Furthermore, using screen filters might help reduce glare and reflections from the screen, especially in situations when sitting with the back to an unshaded window [1]. Majority of students (86.88\%) were not using screen filters, and no association with CVS was observed in our study. Similarly, Reddy et al. reported that using screen filters was not associated with reduced symptoms [14]. However, this is contrary to the finding of Ranasinghe et al. who found significantly higher CVS among those not using screen filters [15]. Shantakumari et al. added that the risk of developing tired and dry eyes was increased among students not using screen filters [16].

Upon assessing the preventive measures taken by students to prevent CVS-related symptoms, a significant association was noted among students who applied the 20-2020 rule and the reduced risk of CVS. Similarly, a study showed that taking frequent breaks every hour for five minutes decreases the discomfort associated with CVS [25]. Reddy et al. added that looking at far objects frequently during work associated significantly with less frequent CVS symptoms [14]. Applying this rule showed improvement in work efficiency in previous studies [26, 27]. Proper location of the screen is another measure that showed significant correlation with reduced risk of CVS. Other measure showed no significant association. Noticeably, most of the students neglected the frequent blinking and using screen filters. Hassan et al. found that most of engineering students were not aware of the correct sitting position [3]. Ranasinghe et al. also provided that knowledge of ergonomics practice was higher among the mild-moderate CVS group than those reported sever CVS symptoms [15].

Limitations of this study include a cross-sectional study design conducted in a single center and CVS diagnosed based on self-reported symptoms without ophthalmic examination. No exclusion criteria were implemented, in which those with preexisting medical or ocular conditions were included, which might have resulted in overestimation of CVS prevalence.

\section{Conclusion}

Computer vision syndrome (CVS) is very common among undergraduate medical students, with excessive tearing, and neck, shoulder, or back pain being the most common symptoms. This study has shown that the development of CVS is associated significantly with the following risk factors: female gender, astigmatism, preexisting dry eye disease, longer duration of computer use, short distance from the screen, and higher brightness of the screen.

The most significant preventive measure taken by students was applying the 20-20-20 rule followed by proper location of the screen. Although there is no risk of permanent 
visual damage, it has been proved that CVS-related symptoms reduce the productivity of work. As universities continuously develop their educational methods, there is a need to raise awareness among students regarding health effects related to prolonged computer use for studying and explain preventive measures in order to reduce CVS symptoms.

\section{Data Availability}

Previously reported data were used to support the findings of this study. The prior studies are cited at relevant places within the text as references [1-27].

\section{Conflicts of Interest}

The authors declare that there are no conflicts of interest regarding the publication of this paper.

\section{Acknowledgments}

The authors would like to express their sincere gratitude to their colleagues for their great help in distributing the survey and collecting the data: Reem Alshareef, Albaraa Alabbadi, Baraa Nogali, Sarah Alessa, Alyazeed Turkistani, Abdulaziz Alsaegh, Lujain Alqurashi, Saja Alghamdi, and Razan Alturkestani.

\section{References}

[1] American Optometric Association, The Effects of Computer Use on Eye Health and Vision, American Optometric Association, St. Louis, MO, USA, 1997, https://www.aoa.org/ Documents/optometrists/effects-of-computer-use.pdf.

[2] A. Ellahi, M. S. Khalil, and F. Akram, "Computer users at risk: health disorders associated with prolonged computer use," Journal of Business Management and Economics, vol. 2, no. 4, pp. 171-182, 2011.

[3] H. M. J. Hassan, S. Ehsan, and H. S. Arshad, "Frequency of computer vision syndrome \& ergonomic practices among computer engineering students," International Journal of Science \& Research, vol. 5, no. 5, pp. 121-125, 2016.

[4] M. Logaraj, V. Priya, N. Seetharaman, and S. Hedge, "Practice of ergonomic principles and computer vision syndrome (CVS) among undergraduates students in Chennai," National Journal of Medical Research, vol. 3, no. 2, pp. 111-116, 2013.

[5] A. Sen and S. Richardson, "A study of computer-related upper limb discomfort and computer vision syndrome," Journal of Human Ergology, vol. 36, no. 2, pp. 45-50, 2007.

[6] M. Gangamma, M. R. Poonam, and M. Rajagopala, "A clinical study on "computer vision syndrome" and its management with triphala eye drops and saptamrita lauha," AYU (An International Quarterly Journal of Research in Ayurveda), vol. 31, no. 2, p. 236, 2010.

[7] J. E. Sheedy, "Vision problems at video display terminals: a survey of optometrists," Journal of the American Optometric Association, vol. 63, no. 10, pp. 687-692, 1992.

[8] A. Hassan, K. Muhammad, and M. Zubair, Eds., "Prevalence of computer vision syndrome (CVS) amongst the students of khyber medical university," in Proceedings of the Islamabad Congress of Ophthalmology, Peshawar, Pakistan, April 2017.

[9] M. Logaraj, V. Madhupriya, and S. Hegde, "Computer vision syndrome and associated factors among medical and engineering students in Chennai," Annals of Medical and Health Sciences Research, vol. 4, no. 2, pp. 179-185, 2014.
[10] K. Loh and S. Redd, "Understanding and preventing computer vision syndrome," Malaysian Family Physician: The Official Journal of the Academy of Family Physicians of Malaysia, vol. 3, no. 3, pp. 128-30, 2008.

[11] S. Wimalasundera, "Computer vision syndrome," Galle Medical Journal, vol. 11, no. 1, 2009.

[12] M. Rosenfield, "Computer vision syndrome: a review of ocular causes and potential treatments," Ophthalmic and Physiological Optics, vol. 31, no. 5, pp. 502-515, 2011.

[13] K. Noreen, Z. Batool, T. Fatima, and T. Zamir, "Prevalence of computer vision syndrome and its associated risk factors among under graduate medical students of urban karachi," Pakistan Journal of Ophthalmology, vol. 32, no. 3, 2016.

[14] S. C. Reddy, C. Low, Y. Lim, L. Low, F. Mardina, and M. Nursaleha, "Computer vision syndrome: a study of knowledge and practices in university students," Nepalese Journal of Ophthalmology, vol. 5, no. 2, pp. 161-168, 2013.

[15] P. Ranasinghe, W. Wathurapatha, Y. Perera et al., "Computer vision syndrome among computer office workers in a developing country: an evaluation of prevalence and risk factors," BMC Research Notes, vol. 9, no. 1, p. 150, 2016.

[16] N. Shantakumari, R. Eldeeb, J. Sreedharan, and K. Gopal, "Computer use and vision-related problems among university students in Ajman, United Arab Emirate," Annals of Medical and Health Sciences Research, vol. 4, no. 2, pp. 258-263, 2014.

[17] S. Munshi, A. Varghese, and S. Dhar-Munshi, "Computer vision syndrome- a common cause of unexplained visual symptoms in the modern era," International Journal of Clinical Practice, vol. 71, no. 7, Article ID e12962, 2017.

[18] N. A. Charpe and V. Kaushik, "Computer vision syndrome (CVS): recognition and control in software professionals," Journal of Human Ecology, vol. 28, no. 1, pp. 67-69, 2009.

[19] M. Guillon and C. Maïssa, "Tear film evaporation-effect of age and gender," Contact Lens and Anterior Eye, vol. 33, no. 4, pp. 171-175, 2010.

[20] L. M. Straker, A. J. Smith, N. Bear, P. B. O’Sullivan, and N. H. de Klerk, "Neck/shoulder pain, habitual spinal posture and computer use in adolescents: the importance of gender," Ergonomics, vol. 54, no. 6, pp. 539-546, 2011.

[21] N. P. Wiggins and K. M. Daum, "Visual discomfort and astigmatic refractive errors in VDT use," Journal of the American Optometric Association, vol. 62, no. 9, pp. 680-684, 1991.

[22] N. P. Wiggins, K. M. Daum, and C. A. Snyder, "Effects of residual astigmatism in contact lens wear on visual discomfort in VDT use," Journal of the American Optometric Association, vol. 63, no. 3, pp. 177-181, 1992.

[23] M. Uchino, D. A. Schaumberg, M. Dogru et al., "Prevalence of dry eye disease among Japanese visual display terminal users," Ophthalmology, vol. 115, no. 11, pp. 1982-1988, 2008.

[24] D. Bhanderi, S. Choudhary, and V. Doshi, "A communitybased study of asthenopia in computer operators," Indian Journal of Ophthalmology, vol. 56, no. 1, p. 51, 2008.

[25] B. S. Levy, G. R. Wagner, K. M. Rest, and J. L. Weeks, Preventing Occupational Disease and Injury, American Public Health Association, Washington, DC, USA, 2nd edition, 2005.

[26] T. Misawa, K. Yoshino, and S. Shigeta, "An experimental study on the duration of a single spell of work on VDT performance," Sangyo Igaku, vol. 26, no. 4, pp. 296-302, 1984.

[27] J. Izquierdo, M. Garcia, C. Buxo, and N. Izquierdo, "Factors leading to the computer vision syndrome: an issue at the contemporary workplace," Boletin de la Asociacion Medica de Puerto Rico, vol. 99, no. 1, pp. 21-28, 2007. 